22 Pritts SD, Susman J. Diagnosis of eating disorders in primary care. Am Fam Physician 2003; 67: 297-304.

23 Ulfvebrand S, Birgegard A, Norring C, Hogdahl L, von Hausswolff-Juhlin Y. Psychiatric comorbidity in women and men with eating disorders results from a large clinical database. Psychiatry Res 2015; 230: 294-9.

24 McElroy SL, Guerdjikova Al, Mori N, Keck PE. Psychopharmacologic treatment of eating disorders: emerging findings. Curr Psychiatry Rep 2015; 17: 35.

25 Mizusaki K, Gih D, LaRosa C, Richmond R, Rienecke RD. Psychotropic usage by patients presenting to an academic eating disorders program. Eat Weight Disord 2018; 23: 769-74.

26 Bulik CM, Klump KL, Thornton L, Kaplan AS, Devlin B, Fichter MM, et al. Alcohol use disorder comorbidity in eating disorders: a multicenter study. J Clin Psychiatry 2004; 65: 1000-6.
27 Krug I, Treasure J, Anderluh M, Bellodi L, Cellini E, Di Bernardo M, et al. Present and lifetime comorbidity of tobacco, alcohol and drug use in eating disorders: a European multicenter study. Drug Alcohol Depend 2008; 97: 169-79.

28 Keel PK, Dorer DJ, Eddy KT, Franko D, Charatan DL, Herzog DB. Predictors of mortality in eating disorders. Arch Gen Psychiatry 2003; 60: 179-83.

29 Button EJ, Chadalavada B, Palmer RL. Mortality and predictors of death in a cohort of patients presenting to an eating disorders service. Int J Eat Disord 2010; 43: 387-92.

30 National Institute for Health and Care Excellence (NICE). Eating Disorders: Recognition and Treatment. NICE, 2017. Available at: https://www.nice.org.uk/ guidance/ng69.

\title{
A state of mind
}

\section{Jack Wellington (iD}

Desolation, despair, desertion, dereliction...

These are the contemplations I face swarming upon the departures gate to my depressive state. Anguish, agitation, alarm, apprehension...

These are the deliberations I face crowded, circling about the arrivals gate upon my return.

Perfidious, pernicious, perilous, pain...

These are the encounters I face at customs, abundant in fury, raging in startling panic.

ominous, omnipotent, onerous, oppression...

These are the conflicts I face, consistent with an inner crusade of obsession lingering outside baggage claim.

Depression, Anxiety, Obsession, Panic.

The words alone unfathomable to comprehend.

I sit alone, isolated in my personal airport of fear.

Fearful of the society I co-inhabit.

Fearful of the prejudice I may witness,

Fearful of abhorrence towards my hidden struggles.

I sit alone, desperate to reach out for support,

support that pays no discrimination, no hate, no repulsion.

Support that has no limits or boundaries.

Support that helps.

Progress, Acceptance, Advancement, Comfort.

These are the antonyms I long await to meet.

For I have been dealt these paradigms,

A life riddled with unsettling uncertainty,

No comfort from society and healthcare,

No one to aid my beckoning cry for help.

But I am paradoxically optimistic.

For I hope to visualise the next generation of healthcare providers, support workers - people,

To speak out against society's perspectives on expressing emotion,

Safeguarding the vulnerable and in need,

The beginning of an accepting world.

This is the place I want to reside.

Not secluded, withering away in my quarantined state of mind.

This is the place I want to be.

Not frightened, panicked and alone.

This is the place I want to become reality.

Reality. Realistic? 